\title{
Only Three Mutations Account for Almost All Defective Alleles Causing Adenine Phosphoribosyltransferase Deficiency in Japanese Patients
}

\author{
Naoyuki Kamatani, Masayuki Hakoda, Sanae Otsuka, Hirofumi Yoshikawa, * and Sadao Kashiwazaki \\ Institute of Rheumatology, Tokyo Women's Medical College, Tokyo 162; and *Institute of Applied Microbiology, \\ University of Tokyo, Tokyo 113, Japan
}

\begin{abstract}
We analyzed mutant alleles of adenine phosphoribosyltransferase (APRT) deficiency in Japanese patients. Among 141 defective APRT alleles from 72 different families, 96 (68\%), 30 (21\%), and $10(7 \%)$ had an ATG to ACG missense mutation at codon 136 ( $A P R T^{*} J$ allele), TGG to TGA nonsense mutation at codon 98, and duplication of a 4-bp sequence in exon 3, respectively. The disease-causing mutations of only four (3\%) of all the alleles among Japanese remain to be elucidated. Thus, a diagnosis can be made for most of the Japanese APRT-deficient patients by identifying only three disease-causing mutations. All of the different alleles with the same mutation had the same haplotype, except for $A P R T^{*} J$ alleles, thereby suggesting that alleles with the same mutation in different families were derived from the same ancestral gene. Evidence for a crossover or gene conversion event within the APRT gene was observed in an $A P R T^{*} J$ mutant allele. Distribution of mutant alleles encoding APRT deficiency among the Japanese was similar to that seen in cystic fibrosis genes among Caucasians and Tay-Sachs genes among the Ashkenazi Jews. (J. Clin. Invest. 1992. 90:130-135.) Key words: purine • intragenic • recombination • crossover • evolution
\end{abstract}

\section{Introduction}

Ethnic variation in inherited diseases is widely acknowledged, and some autosomal recessive disorders are present at rather high incidences among certain populations. The frequencies of heterozygotes of cystic fibrosis among Caucasians, and TaySachs disease among the Ashkenazi Jews, were estimated to be $3 \%$ and $2.6-3.2 \%$ (1), respectively. Hemoglobinopathies and thalassemias are also common among populations living in tropical and subtropical areas (1). Other genetic diseases with ethnic variations include $\alpha 1$-antitrypsin and phenylalanine hydroxylase deficiencies among Caucasians and Gaucher's disease and Nieman-Pick disease among the Ashkenazi Jews (1). It has become apparent that adenine phosphoribosyltransferase $(\mathrm{APRT})^{1}$ deficiency may be one such disease since the

Address reprint requests to Dr. Kamatani, Institute of Rheumatology, Tokyo Women's Medical College, KS Bldg., 9-12 Wakamatsu-cho, Shinjuku-ku, Tokyo 162, Japan.

Received for publication 4 October 1991 and in revised form 14 January 1992.

1. Abbreviations used in this paper: APRT, adenine phosphoribosyltransferase; ASO, allele-specific oligonucleotide; PCR, polymerase chain reaction.

J. Clin. Invest.

(c) The American Society for Clinical Investigation, Inc. $0021-9738 / 92 / 07 / 0130 / 06 \$ 2.00$

Volume 90 , July 1992, 130-135 estimated gene frequency ( $1.2 \%)$ suggests that it is one of the most common autosomal recessive disorders among the Japanese (2), and the majority of the patients so far described belong to this population $(3,4)$. Data on $\sim 70$ Japanese families with homozygous APRT deficiency have been reported (reference 4 and other papers); the number of non-Japanese families with this deficiency is $\sim 36$ (Simmonds, H. A., personal communication).

We analyzed 141 mutant alleles in 72 separate Japanese families with APRT deficiency. Individuals homozygously deficient in this enzyme develop urolithiasis and, in severe cases, renal failure occurs (3). Two different mutations have been identified among the Japanese; the most common mutant allele $A P R T^{*} J$ with a missense mutation at codon 136 from ATG to ACG (5) is known to represent $\sim 70 \%$ of all the mutant alleles (4), and in patients with 2,8-dihydroxyadenine urolithiasis with this mutant allele there is a partial enzyme deficiency, as determined by in vitro enzyme assay (type II deficiency) (3). Another mutation (nonsense mutation at codon 98 from TGG to TGA) has been identified $(6,7)$, but it is not clear what fraction of mutant alleles carries this mutation.

We report here evidence that $96 \%$ of the mutant alleles among the Japanese patients can be explained by three different disease-related mutations. Mutant alleles with the same mutation were probably derived from a single ancestral gene.

\section{Methods}

Patients and diagnostic methods. 39 of the 72 families reported here are the same families examined in reference 4 . In 69 of the 72 families, the propositi had either 2,8-dihydroxyadenine urolithiasis (67 families) or crystalluria ( 2 families). Blood samples were sent to our laboratory for diagnostic purposes. The correct diagnosis of homozygous APRT deficiency can be made by using T cells; enzyme assay alone will not lead to a correct diagnosis (6). The method we used for diagnosing homozygotes for APRT deficiency was as described elsewhere (6). We found that all the 69 propositi were homozygotes (In this context, a homozygote is designated as an individual with two defective APRT alleles, and this definition includes compound heterozygotes). The remaining three families had heterozygotes but not homozygotes. These families were identified during screening for heterozygotes for APRT deficiency, using the somatic cell mutation method, as described elsewhere (7). All three heterozygotes had neither 2,8-dihydroxyadenine urolithiasis nor crystalluria.

Southern blots. DNA was prepared from either mononuclear cells from the peripheral blood from various individuals or from B cell lines, by the phenol extraction method, as described (7). For Southern blotting, 2-5 $\mu \mathrm{g}$ of DNA was digested with one of the restriction endonucleases, under conditions recommended by the supplier. The digested DNA was used for agarose-gel electrophoresis and was then blotted onto nylon membranes (Biodyne A, pall Biosupport Corp., Glen Cove, NY). Procedures used for hybridization of the blotted DNA with human APRT cDNA probe were as described elsewhere (7). Human APRT cDNA was kindly provided by Dr. Y. Hidaka (University of Michigan, Ann Arbor, MI). 
Polymerase chain reaction ( $P C R)$. All the coding regions of human genomic APRT DNA, including all the exons, were amplified by two separate PCR reactions. Thus, a fragment including exons 1 and 2 was amplified by one procedure, whereas another fragment including exons 3,4 , and 5 was amplified by a separate procedure. Methods for the amplification of part of the human APRT gene, including exons 3, 4, and 5 by the PCR method by using primers PN13 (5'-CCGAGTCACTCCTGTCACTTA-3') and PN14 (5'-GGATCCAGCTGGAGATGTTGGGCT-3'), were as described (7). A fragment including exons 1 and 2 was amplified by using synthetic primers, PN11 (5'-ATCGATGGCGCCTAGGAGTCCA-3') and PN12 (5'-AGAGGCGGAAGCGCCCTAGAT-3'). PN11 has the sequence of base positions -165 to -144 of human APRT gene (base " $C$ " located one base 5' of the initiation codon "ATG" was counted as -1 ), whereas PN12 anneals to the sequence of base positions 373 to 393 (base " $A$ " in the initiation codon "ATG" was counted as 1 ) of the human genomic APRT sequence. The conditions for PCR using PN11 and PN12 were essentially the same as those for PCR using PN13 and PN14 (7), except that the annealing temperature for the former was $62.5^{\circ} \mathrm{C}$. To sequence the amplified fragments, the resulting mixture after PCR was used for agarose-gel electrophoresis and the amplified DNA band was cut out from the gel. DNA was then purified from the agarose gel after dissolving the agarose in $\mathrm{NaI}$ and binding the DNA to glass, essentially as described by Vogelstein and Gillespie (8) and using a GENECLEAN II kit (BIO101, La Jolla, CA). Single-stranded DNA templates were generated by asymmetric amplification using $100 \mathrm{pmol}$ of one oligonucleotide primer and 1 pmol of the other (9). Amplification was carried out for 35 cycles and sequencing was done directly by the dideoxy-chain termination method (10) and Sequenase sequencing kit version II (U. S. Biochemical Corp., Cleveland, $\mathrm{OH}$ ).

Allele-specific oligonucleotide (ASO) hybridization. Genomic DNA was used for the same PCR amplification system as described above and part of the obtained mixture containing the amplified sequence was slot-blotted onto nylon membranes (Biodyne A, Pall Biosupport Corp.). Selective hybridization of biotin-labeled probes and the subsequent chemiluminescence procedures were performed essentially as described elsewhere (11), using different probes. The membranes were exposed to $\mathrm{x}$-ray films. Sequences of the synthetic oligonucleotide probes used for identification of mutant and normal sequences are shown in Table I. In all the cases, selective hybridization to both normal and mutant sequences was done in parallel experiments (11). Thus, the solution used for identification of the normal sequence contained biotin-labeled normal and nonlabeled mutant sequences, whereas that used for the identification of mutant sequence contained biotin-labeled mutant and nonlabeled normal sequences (11).

In some experiments, radiolabeled probes instead of biotin-labeled probes were used. The procedures used were described in detail elsewhere (4).

\section{Results}

Detection of mutant alleles by Southern blots. Hidaka et al. (5) identified a Japanese individual with type I APRT deficiency in whom the APRT gene showed an unusual restriction fragment length polymorphic band after treatment with TaqI; when di- gested with $T a q \mathrm{I}$ it showed a 1.8-kb band instead of the common 2.1- or 2.8-kb band. The DNA showed unusual bands when digested with various restriction enzymes (data not shown), thereby suggesting that a gross alteration of the APRT gene is the cause of the deficiency. The exact alteration of the change remains to be elucidated.

Besides this allele with a gross DNA alteration, all of the other defective alleles tested showed normal Southern blot patterns when digested with either TaqI or SphI (data not shown). Thus, they exhibited either $2.1-$ or $2.8-\mathrm{kb}$ bands when digested with TaqI (12), and either 8- or 12-kb bands when digested with $S p h \mathrm{I}$ (13). Therefore, the mutations in these alleles are minor and do not affect Southern blot patterns.

Identification of a disease-related mutation by sequencing. Two mutations ( $A P R T^{*} J$ allele: ATG to ACG missense mutation at codon 136, TGG to TGA nonsense mutation at codon 98 ) have already been described $(5,14,15)$; these two mutations are frequent in APRT-deficient alleles among the Japanese. Using the PCR-ASO hybridization method (as described below), we found that $14(10 \%)$ of the mutant alleles had neither of the above-mentioned point mutations. Since all of these alleles showed normal restriction fragment length polymorphic patterns, we expected to find minor gene changes. We attempted to determine mutation(s) in one of the homozygotes having neither of the known mutations by using DNA from a B cell line (WR181) from the subject. We identified a duplication of the 4-bp sequence (CCGA) normally located at base positions 1417 to 1420 ("A" in the initiation codon ATG was counted as 1) by sequencing of the PCR-amplified genomic DNA fragments, including all the coding sequences (Fig. 1). This duplication in exon 3 should lead to a shift in the reading frame of the coding sequence, and codon 110 should become a stop codon (TGA). There were no other base changes in the exons, $3^{\prime}$ or $5^{\prime}$ flanking sequences, or the exon-intron junction sequences. Therefore, it is likely that this change (4-bp duplication) is the direct cause of the defective phenotype. Finding the same mutation in eight additional defective APRT alleles (as stated below) provided additional evidence that this mutation is the direct cause of the deficiency. WR 181 is considered to be homozygous for this mutation, since PCR-amplified DNA from this cell line hybridized only with the mutant allele-specific but not with the normal allele-specific oligonucleotide. A germ line mutation by a duplication leading to an APRT deficiency has heretofore not been described.

Identification of mutations by PCR-ASO hybridization methods. All three mutations listed above are located in exons 3-5. We amplified a DNA segment including exons 3-5 of the genomic APRT DNA by PCR, as described in Methods. After the amplified DNA had been slot-blotted onto membranes, hybridization was carried out with biotin-labeled ASOs in the presence of competitive sequences (11). This system revealed

Table I. Allele-specific Oligonucleotide Probes Used For Detection of Mutant Alleles

\begin{tabular}{lll}
\multicolumn{1}{c}{ Mutation } & \multicolumn{1}{c}{ Normal } & Mutant \\
ATG to ACG at codon 136 & CAGGAACCAtGAACGCTGC & CAGGAACCAcGAACGCTGC \\
TGG to TGA at codon 98 & CACTCTGTGgGCcTCCTAT & CACTCTGTGaGCtTCCTAT \\
4-bp insertion in exon 3 & TGCTCATCCGAAAGCGGGG & CTCATCCGA(ccga)AAGCGG
\end{tabular}

Nucleotide sequences are expressed from $5^{\prime}$ (left) to $3^{\prime}$ (right). Small letters denote differences between normal and mutant sequences. 


\section{Control}

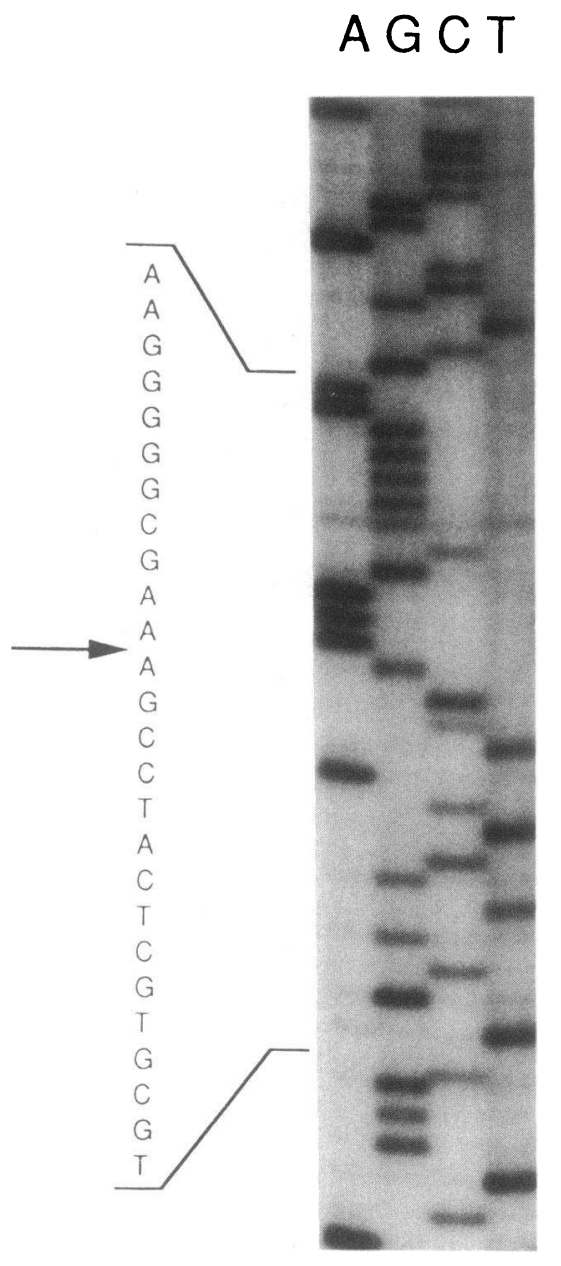

WR181

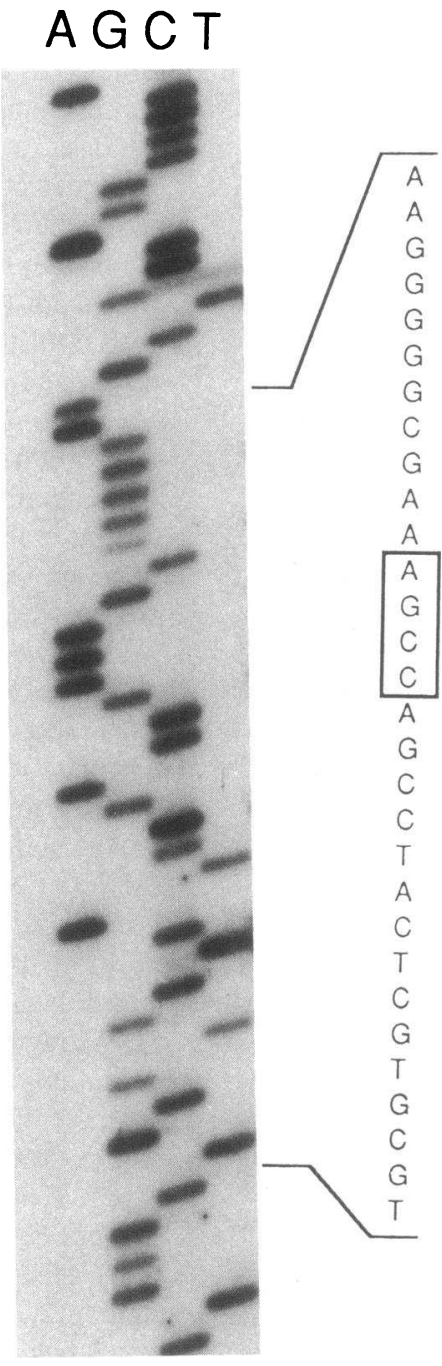

Figure 1. Sequence near the mutation site of the genomic APRT gene from WR181 (B cell line from a DHA lithiasis patient) as compared with that of a control subject. PCR-amplified fragments were directly sequenced. The sequences are shown from bottom $\left(5^{\prime}\right)$ to top $\left(3^{\prime}\right)$. WR181 had a 4-bp insertion at the point shown by an arrow in exon 3 , the result being a duplication of CCGA, as indicated by the boxed area. three different mutations and whether each individual is a heterozygote or a homozygote for the mutation. Fig. 2 shows the results of the biotin-labeled oligonucleotide hybridization for detection of the 4-bp duplication for samples from homozygotes, heterozygotes, or control subjects. Equivalent methods were used to detect the other two mutations (data not shown). In some experiments, ASO hybridization was performed by using ${ }^{32} \mathrm{P}$-labeled ASO probes, without competitive sequences. When the samples from the same individuals were tested by both radioactive and nonradioactive methods, the results were always consistent.

Using a combination of Southern blot analysis and PCRASO hybridization methods, we examined individuals who were homozygotes or heterozygotes for APRT deficiency. Among the 69 homozygous propositi, 2 carried alleles with none of the four different mutations (including gross alteration) described here. In the remaining 67 , the mutations of all the alleles were identified. 43 had a genotype of $A P R T^{*} J /$ $A P R T^{*} J$ and 8 had another mutation in addition to $A P R T^{*} J$ (genotype $A P R T^{*} J / A P R T^{*} Q O$ ). In seven of the eight propositi with the genotype of $A P R T^{*} J / A P R T^{*} Q O, A P R T^{*} Q O$ alleles had a TGG to TGA change at codon 98; the remaining one had a 4-bp insertion in exon 3 . The 16 homozygous propositi had a genotype of $A P R T^{*} Q O / A P R T^{*} Q O$. In 11 , both $A P R T^{*} Q O$ alleles had a TGG to TGA change at codon 98 whereas 4 had a 4-bp insertion in exon 3 in both alleles. One was a compound heterozygote having a TGG to TGA change at codon 98 and gross alteration. Two of the three heterozy-

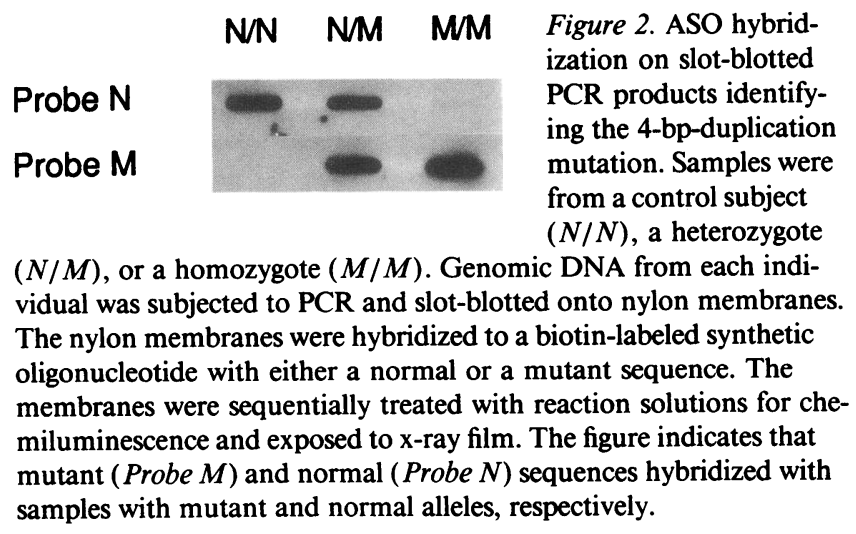


Table II. Composition of Disease-causing

Mutant Alleles of APRT Deficiency

\begin{tabular}{lrr}
\multicolumn{1}{c}{ Mutant allele } & Number & Percentage \\
\hline$A P R T^{*} J$ (ATG to ACG at codon 136) & 96 & 68 \\
TGG to TGA at codon 98 & 30 & 21 \\
4-bp insertion in exon 3 & 10 & 7 \\
Gross alteration & 1 & 1 \\
Undefined & 4 & 3 \\
Total & 141 & 100 \\
\hline
\end{tabular}

gotes had $A P R T^{*} J$ alleles whereas one had a $A P R T^{*} Q O$ allele (4-bp insertion in exon 3). Our previous studies showed no clear differences in phenotypes between type I and type II APRT deficiencies (16). Age at the time of diagnosis (not necessarily the same as age at onset of symptoms) was available for a limited number of patients: $31.4 \pm 19.5 \mathrm{y}($ mean \pm SD) for 37 propositi with the genotype of $A P R T^{*} J / A P R T^{*} J$ and $24.1 \pm 17.6 \mathrm{yr}$ for 16 propositi with the genotype of $A P R T^{*} Q O /$ $A P R T^{*} Q O$. Seven propositi with the genotype of $A P R T^{*} J /$ $A P R T^{*} Q O$ were age $33.3 \pm 28.1 \mathrm{yr}$ when the diagnosis was made. There was no statistical significance (Mann-Whitney $U$ test) in differences of age at the diagnosis between three different genotypes. Other data, including the percentage of homozygotes with only crystalluria and the percentage of homozygotes with severe renal failure, showed no evidence for the difference in phenotypes or the severity of the disease between homozygous propositi with different genotypes $\left(A P R T^{*} J / A P R T^{*} J, A P R T^{*} J / A P R T^{*} Q O\right.$, and $A P R T^{*} Q O /$ $\left.A P R T^{*} Q O\right)$.

Table II is a summary of the numbers and percentages of the mutant alleles found in separate families. When a homozygote in a family had two defective alleles with the same mutation, the family was counted as having two mutant alleles with this mutation. Since 3 of the 72 families had only heterozygotes, the total number of defective APRT alleles we examined was 141 (Since $69 \times 2+3=141$ ). Among the 141 defective APRT alleles from 72 different families, $96(68 \%), 30(21 \%)$,
$10(7 \%)$, and $1(1 \%)$ had an ATG to ACG missense mutation at codon 136 ( $A P R T^{*} J$ allele), TGG to TGA nonsense mutation at codon 98, duplication of the 4-bp sequence in exon 3, and a gross DNA alteration, respectively (Table II). The remaining four (3\%) alleles are the subject of ongoing study.

RFLP analysis. Three different polymorphic sites ( Sph, $\mathrm{h} T a q, \mathrm{p} T a q)$ have been described $(4,12,13)$ near and within the APRT gene. As indicated in the physical genomic map (4), $\mathrm{h} T a q$ is located in intron 2 whereas $S p h$ and $\mathrm{p} T a q$ are located in the $5^{\prime}$ and 3 ' flanking regions, respectively, of the APRT gene. Using these three polymorphic sites, APRT alleles among the Japanese can be classified into four common and two rare haplotypes, except for the deficient allele with a major gene change (4). We determined haplotypes of 94 APRT-deficient alleles. As shown in Table III, the most common $A P R T^{*} J$ mutant alleles were classified into three haplotypes. About $90 \%$ $(60 / 67)$ had a +-+ haplotype, whereas most of the remaining alleles $(6 / 67)$ had a --+ haplotype. One $A P R T^{*} J$ allele showed another haplotype, +++ ( Table III ). In contrast, all of the other mutant alleles showed the same haplotype when the same mutation was present. Thus, all the defective alleles with the TGG to TGA substitution at codon 98 had a +++ haplotype and all of those with a 4-bp duplication in exon 3 had a -++ haplotype (Table III).

\section{Discussion}

The present investigations revealed that $96 \%$ of the 141 APRTdeficient alleles from 72 Japanese families were caused by only three different mutations. Among the remaining five mutant alleles, one had a gross DNA alteration; mutation(s) of the other four alleles have yet to be identified. Including the new cases reported here, the total number of homozygous APRTdeficient families described in the world literature will be $\sim 130$; the present paper includes more than a half this number. These patients are from various areas of the Japan archipelago, hence, is unlikely that the frequency of each mutant allele described here will change grossly. Using the method described in this manuscript, most of the Japanese APRT-deficient patients and heterozygotes can be directly diagnosed by detection of disease-related mutations.

Table III. Haplotypes of APRT Alleles

\begin{tabular}{|c|c|c|c|c|c|c|c|}
\hline \multicolumn{3}{|c|}{$\begin{array}{l}\text { Restriction fragment length } \\
\text { polymorphism sites }\end{array}$} & \multirow[b]{2}{*}{$\begin{array}{l}A P R T^{*} 1 \\
\text { (normal) }\end{array}$} & \multirow{2}{*}{$\begin{array}{c}A P R T^{*} J \\
\text { (ATG to ACG } \\
\text { at codon } 136 \text { ) }\end{array}$} & \multicolumn{3}{|c|}{$A P R T^{*} Q 0$} \\
\hline$S p h$ & $\mathrm{~h} T a q$ & $\mathrm{p} T a q$ & & & $\begin{array}{l}\text { TGG to TGA } \\
\text { at codon } 98\end{array}$ & $\begin{array}{l}\text { 4-bp Duplication } \\
\text { in exon } 3\end{array}$ & $\begin{array}{l}\text { Gross } \\
\text { alteration }\end{array}$ \\
\hline+ & + & + & 42 & 1 & 19 & 0 & 0 \\
\hline- & + & + & 42 & 0 & 0 & 7 & 0 \\
\hline+ & - & + & 40 & 60 & 0 & 0 & 0 \\
\hline- & - & + & 68 & 6 & 0 & 0 & 0 \\
\hline- & + & - & 1 & 0 & 0 & 0 & 0 \\
\hline+ & - & - & 1 & 0 & 0 & 0 & 0 \\
\hline \multicolumn{3}{|c|}{ Gross alteration } & 0 & 0 & 0 & 0 & 1 \\
\hline \multicolumn{3}{|l|}{ Total } & 194 & 67 & 19 & 7 & 1 \\
\hline
\end{tabular}

Locations of the polymorphic restriction sites, Sph, hTaq, and pTaq (4). + and - indicate that DNA on the chromosome having each haplotype is $(+)$ or is not $(-)$ cut by restriction endonuclease. 

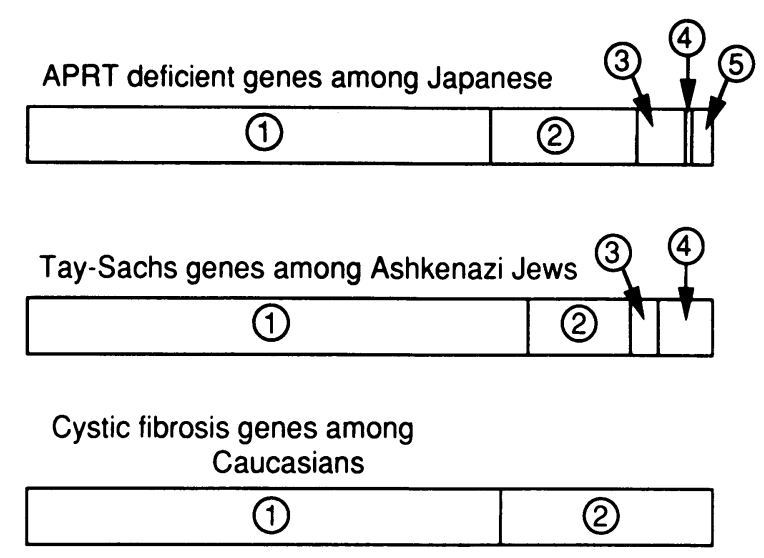

1. $A P R T^{*}$ J (ATG to ACG at codon 136)

2. TGG to TGA at codon 98

3. $4 \mathrm{bp}$ insertion in exon 3

4. major gene change

5. undefined

1. $4 \mathrm{bp}$ insertion in exon 11

2. $G$ to $C$ at $5^{\prime}$ splice site in intron 12

3. GGT to AGT in exon 7

4. undefined

1. $\Delta \mathrm{F} 508$ (3pb deletion in exon 10$)$

2. miscellaneous and undefined
Figure 3. Distribution of defective alleles encoding APRT deficiency among Japanese as well as that of cystic fibrosis among Caucasians and that of Tay-Sachs disease among Ashkenazi Jews. Each bar shows the relative proportions of each mutation.
When the distribution of mutant alleles encoding APRT deficiency among the Japanese was compared with that of other diseases in other populations, there was a similarity to that of cystic fibrosis among Caucasians and that of Tay-Sachs disease among the Ashkenazi Jews (Fig. 3). Thus, the most common mutations represent $\sim 70 \%$ of all the mutant alleles, and the less common mutations follow $(17,18)$. In Tay-Sachs disease and APRT deficiency, there are second and third common mutations (reference 17 and this manuscript). Common mutant alleles have also been identified in $\alpha 1$-antitrypsin deficiency (19), phenylalanine hydroxylase deficiency $(20,21)$, and medium-chain acyl-CoA dehydrogenase deficiency (22, 23) among Caucasians; hemoglobinopathies and thalassemias in groups living in tropical and subtropical areas (24-26); and Gaucher's disease among the Ashkenazi Jews (27), although the percentages of the most frequent alleles do differ from the above mentioned three diseases. As the three diseases with intergroup variation (cystic fibrosis, Tay-Sachs disease and APRT deficiency) have other similarities, each is one of the most common autosomal recessive genetic diseases in each population. Not only the composition of mutant alleles but also the origins seem to be similar. Our study shows that except for $A P R T^{*} J$ alleles, those with the same mutation at the APRT gene have the same haplotype, thereby suggesting that they derive from a single mutation. Although $A P R T^{*} J$ alleles had three different haplotypes, this can be explained by crossovers or gene conversions, as described below, and does not exclude the possibility of a single origin (4). In the case of cystic fibrosis, the $\Delta \mathrm{F} 508$ mutation was found to be always associated with the six 4-bp repeats in intron 6; hence, alleles with the same disease-related mutation probably derive from a common origin (28). These similarities suggest that there is a common factor in the mechanism of the expansion of the disease-causing genes in each population.

High mutation rates at certain loci, compensating advantages, or random genetic drift may be responsible for the high frequencies of the defective alleles of some genetic diseases (29-33). A high mutation theory can be excluded because each genetic disease is common only in a single population. The close association between each mutation and closely linked polymorphic sites also argues against the high mutation theory. Either random genetic drift or compensating advantages (or both) is a likely mechanism. In cases of cystic fibrosis and TaySachs disease, there is not sufficient evidence for an heterozygous or compensating advantage, although various possible se- lective advantages to the gene carriers have been suggested ( 30 , 34). There is no evidence for a selective advantage for APRT deficiency.

One interesting finding was the intragenic crossover or a gene conversion event. Various pieces of evidence support that all $A P R T^{*} J$ alleles have derived from a common ancestor (4). About $90 \%$ of all the $A P R T^{*} J$ alleles had a haplotype of +-+ , hence, the mutation probably occurred on a chromosome with this haplotype. The presence of an $A P R T^{*} J$ allele with a +++ haplotype can be explained by a crossover or a gene conversion event in which a junction site is between the $A P R T^{*} J$ mutation site and hTaq polymorphic site. Since hTaq and the $A P R T^{*} J$ mutation sites are in intron 2 and exon 5, respectively, it probably was an intragenic crossover or a gene conversion. Although intragenic germ line recombination rarely occurs, it can do so even within a short distance in the course of many generations.

\section{Acknowledgments}

We express our appreciation to $\mathrm{M}$. Ohara for helpful comments and also to the doctors who sent us samples to examine for APRT deficiency.

This work was supported by a Grant-in-Aid to Scientific Research from the Ministry of Education, Science, and Culture, Japan, and a research grant for intractable diseases from the Ministry of Health and Welfare, Japan.

\section{References}

1. McKusick, V. A. 1988. Mendelian Inheritance in Man. 8th ed. Johns Hopkins University Press, Baltimore, MD. 1626 pp.

2. Kamatani, N., T. Sonoda, and K. Nishioka. 1988. Distribution of the patients with 2,8-dihydroxyadenine urolithiasis and adenine phosphoribosyltransferase deficiency in Japan. J. Urol. 140:1470-1472.

3. Simmonds, H. A., A. S. Sahota, and K. J. Van Acker. 1989. Adenine phosphoribosyltransferase deficiency and 2,8-dihydroxyadenine lithiasis. In Metabolic Basis of Inherited Disease. 6th ed. C. R. Scriver, A. L. Beaudet, W. S. Sly, and D. Valle, editors. McGraw-Hill, Inc., New York. 1029-1044.

4. Kamatani, N., S. Kuroshima, M. Hakoda, T. D. Palella, and Y. Hidaka. 1990. Crossovers within a short DNA sequence indicate a long evolutionary history of $A P R T^{*} J$ mutation. Hum. Genet. 85:600-604.

5. Hidaka, Y., S. A. Tarle, S. Fujimori, N. Kamatani, W. N. Kelley, and T. D. Palella. 1988. Human adenine phosphoribosyltransferase deficiency: demonstration of a single mutant allele common to the Japanese. J. Clin. Invest. 81:945950.

6. Kamatani, N., F. Takeuchi, Y. Nishida, H. Yamanaka, K. Nishioka, K. Tatara, S. Fujimori, K. Kaneko, I. Akaoka, and Y. Tofuku. 1985. Severe impairment in adenine metabolism with a partial deficiency of adenine phosphoribosyltransferase. Metab. Clin. Exp. 34:164-168. 
7. Hakoda, M., H. Yamanaka, N. Kamatani, and N. Kamatani. 1991. Diagnosis of heterozygous states for adenine phosphoribosyltransferase deficiency based on detection of in vivo somatic mutants in blood $\mathrm{T}$ cells: application to screening of heterozygotes. Am. J. Hum. Genet. 48:522-562.

8. Vogelstein, B., and D. Gillespie. 1979. Preparative and analytical purification of DNA from agarose. Proc. Natl. Acad. Sci. USA. 76:615-619.

9. Sambrook, J., E. F. Fritsch, and T. Maniatis. 1989. Molecular Cloning: A Laboratory Manual. 2nd ed. Cold Spring Harbor Laboratory, Cold Spring Harbor, NY.

10. Sanger, F., S. Nicklen, and A. R. Coulson. 1977. DNA sequencing with chain-terminating inhibitors. Proc. Natl. Acad. Sci. USA. 74:5463-6467.

11. Kawaguchi, R., H. Higashimoto, K. Hikiji, M. Hakoda, and N. Kamatani. 1991. Detection of the most common mutation of adenine phosphoribosyltransferase deficiency among Japanese by a non-radioactive method. Clin. Chim Acta. 203:183-190.

12. Stambrook, P. J., M. D. Dush, J. J. Trill, and J. A. Tishfield. 1984. Cloning of a functional human adenine phosphoribosyltransferase (APRT) gene: identifcation of a restriction fragment length polymorphism and preliminary analysis of DNAs from APRT-deficient families and cell mutants. Somatic Cell. Mol. Genet. 10:359-367.

13. Arrand, J. E., A. M. Murray, and N. Spurr. 1987. Sph I restriction fragment length polymorphism on human chromosome 16 detected with an APRT gene probe. Nucleic Acids Res. 15:9615.

14. Sahota, A., J. Chen, K. Asaki, H. Takeuchi, P. J. Stambrook, and J. A. Tischfield. 1990. Identification of a common nonsense mutation in Japanese patients with type I adenine phosphoribosyltransferase deficiency. Nucleic Acids Res. 18:5915-5920.

15. Mimori, A., Y. Hidaka, V. C. Wu, S. A. Tarle, N. Kamatani, W. N. Kelley, and T. D. Palella. 1991. A mutant allele common to the type I adenine phosphoribosyltransferase deficiency in Japanese subjects. Am. J. Hum. Genet. 48:102107.

16. Kamatani, N., C. Terai, S. Kuroshima, K. Nishioka, and K. Mikanagi. 1987. Genetic and clinical studies on 19 families with adenine phosphoribosyltransferase deficiencies. Hum. Genet. 75:163-168.

17. Paw, B. H., P. T. Tieu, M. M. Kaback, J. Lim, and E. F. Neufeld. 1990. Frequency of three Hex A mutant alleles among Jewish and non-Jewish carriers identified in a Tay-Sachs screening program. Am. J. Hum. Genet. 47:698-705.

18. Riordan, J. R., J. M. Rommens, B.-S. Kerem, N. Alon, R. Rozmahel, Z. Grzelczak, J. Zielenski, S. Lok, N. Plavsic, J.-L. Chou, et al. 1989. Identification of the cystic fibrosis gene: cloning and characterization of complementary DNA. Science (Wash. DC). 245:1066-1080.

19. Cox, D. W., S. L. C. Woo, and T. Mansfield. 1985. DNA restriction fragment associated with $\alpha 1$-antitrypsin indicate a single origin for deficiency allele PI Z. Nature (Lond.). 316:79-81.
20. Woo, S. L. C., A. S. Lidsky, F. Guttler, T. Chandra, and J. H. Robson. 1983. Cloned human phenylalanine hydroxylase gene allows prenatal diagnosis and carrier deletion of classical phenylketonuria. Nature (Lond.). 306:151-155.

21. DiLella, A. G., J. Marvit, A. S. Lidsky, F. Guttler, and S. L. C. Woo. 1986. Tight linkage between a splicing mutation and a specific DNA haplotype in phenylketonuria. Nature (Lond.). 322:799-803.

22. Matubara, Y., K. Narisawa, S. Miyabayashi, K. Tada, and P. M. Coates. 1990. Molecular lesion in patients with medium-chain acyl-CoA dehydrogenase deficiency. Lancet. 335:1589.

23. Yokota, I., K. Tanaka, P. M. Coates, and M. Ugarte. 1990. Mutations in medium chain acyl-CoA dehydrogenase deficiency. Lancet. 336:748.

24. Orkin, S. H., H. H. Kazazian, Jr., and S. E. Antonarakis. 1982. Linkage of $\beta$-thalassemia mutations and $\beta$-globin gene polymorphism with DNA polymorphism in the $\beta$-globin gene cluster. Nature (Lond.). 269:627-631.

25. Antonarakis, S. E., H. H. Kazazian, Jr., and S. H. Orkin. 1985. DNA polymorphism and molecular pathology of the human globin gene clusters. Hum Genet. 16:1-14.

26. Wong, C., S. E. Antonarakis, S. C. Goff, S. H. Orkin, C. D. Boehm, and H. H. Kazazian, Jr. 1986. On the origin and spread of $\beta$-thalassemia; recurrent observation of four mutations in different ethnic groups. Proc. Natl. Acad. Sci. USA. 83:6529-6532.

27. Tsuji, S., P. V. Choudary, B. M. Martin, B. K. Stubblefield, J. A. Mayor, J. A. Barranger, and E. I. Ginns. 1987. A mutation in the human glucocerebrosidase gene in neuronopathic Gaucher's disease. N. Engl. J. Med. 316:570-575.

28. Chehab, F. F., J. Johnson, E. Louie, M. Goossens, E. Kawasaki, and H. Erlich. 1991. A dimorphic repeat in the cystic fibrosis gene is in absolute linkage disequilibrium with the $\Delta \mathrm{F} 508$ mutation: implications for prenatal diagnosis and mutation origin. Am. J. Hum. Genet. 48:223-226.

29. Vogel, F., and A. G. Motulsky. 1986. Genetic drift in cooperation with mutation and selection. Hum. Genet. 81:506-511.

30. Rotter, J. I., and J. M. Diamond. 1987. What maintains the frequencies of human genetic diseases? Nature (Lond.). 329:289-290.

31. Romeo, G., M. Devoto, and L. J. V. Galietta. 1989. Why is the cystic fibrosis gene so frequent? Hum. Genet. 84:1-5.

32. Arpaia, E., A. Dumbrille-Ross, T. Maler, K. Neote, M. Tropak, C. Troxel, J. L. Stirling, J. S. Pitts, B. Bapat, A. M. Lamhonwah, et al. 1988. Identification of an altered splice site in Ashkenazi Tay-Sachs disease. Nature (Lond.). 333:85-86.

33. Curiel, D., M. Brantly, E. Curiel, L. Stier, and R. Crystal. 1989. $\alpha 1$-antitrypsin deficiency caused by the $\alpha 1$-antitrypsin null Mattawa gene. An insertion mutation rending the $\alpha 1$-antitrypsin gene incapable of producing $\alpha 1$-antitrypsin. J. Clin. Invest. 83:1144-1152.

34. Boat, T. F., M. J. Welsh, and A. L. Beaudet. 1989. Cystic fibrosis. In Metabolic Basis of Inherited Disease. 6th ed. C. R. Scriver, A. L. Beaudet, W. S. Sly, and D. Valle, editors. McGraw-Hill, Inc. New York. 2649-2680. 